\title{
Rendimentos do Abate e Carcaça de Bovinos e Bubalinos Castrados e Inteiros ${ }^{1}$ Victor Cruz Rodrigues ${ }^{2}$, Ivo Francisco de Andrade ${ }^{3}$, Rilke Tadeu de Freitas ${ }^{4}$, Maria Cristina Bressan $^{5}$, Júlio César Teixeira ${ }^{6}$
}

\begin{abstract}
RESUMO - Foram abatidos 24 animais confinados, sendo 8 ( 4 castrados e 4 inteiros) de cada grupo genético (bovinos Nelore, $1 \frac{2}{2}$ Nelore x Sindi e bubalinos Mediterrâneos) com peso médio de $430 \mathrm{~kg}$, objetivando-se comparar os rendimentos do abate e da carcaça. Os dados obtidos foram estatisticamente analisados em um esquema fatorial 3 x 2 (três grupos genéticos e duas condições sexuais) com quatro repetições. Bovinos Nelore e $1 \frac{1}{2}$ Nelore $x$ Sindi apresentaram menor porcentual de patas $(2,13 ; 2,08$ vs $2,31 \%)$, cabeça $(3,99 ; 4,48$ vs $5,04 \%)$, couro $(7,45 ; 8,21$ vs $9,92 \%)$ e vísceras $(25,6 ; 25,1$ vs $28,4 \%)$ que búfalos, mas não houve diferença entre inteiros e castrados para rendimento das patas e vísceras. Animais castrados apresentaram couro com menor porcentual que inteiros ( $8,20 \mathrm{vs} 8,85 \%)$, semelhante porcentagem da cabeça, sendo que o porcentual da rabada foi maior nos animais castrados $(0,29$ vs $0,26 \%)$. Os rendimentos da carcaça e dos cortes da carcaça em relação ao peso de abate foram maiores nos bovinos Nelore e $1 / 2$ Nelore x Sindi que búfalos: carcaça (60,6 e 59,9 vs 54,1\%), serrote (27,98 e 27,1 vs 25,6\%), dianteiro (24,8 e 24,9 vs 20,3\%) com semelhança para o costilhar (7,82 e 7,83 vs 8,23\%), enquanto os inteiros apresentaram maior corte dianteiro (23,9 vs $22,8 \%$ ) que castrados. Para os rendimentos da carcaça e seus cortes em relação ao peso da carcaça, os bovinos Nelore e $1 / 2$ Nelore $\mathrm{x}$ Sindi alcançaram maior rendimento (58,7 e 58,1 vs 52,3\%) que búfalos, enquanto castrados e inteiros foram semelhantes. Bovinos Nelore e $1 / 2$ Nelore x Sindi alcançaram menor rendimento do corte serrote que búfalos (46,7; 45,9 vs 47,8\%), enquanto os animais castrados apresentaram maior rendimento do serrote que inteiros (47,3 vs 46,3\%). Bovinos Nelore e $1 / 2$ Nelore $x$ Sindi alcançaram maior rendimento do corte dianteiro $(40,7 ; 41,4$ vs $37,4 \%)$, que bubalinos, bem como os animais inteiros (40,7 vs 38,9\%) em relação aos castrados. O rendimento do corte costilhar foi menor nos bovinos Nelore e $1 \frac{1}{2}$ Nelore x Sindi (12,9; 13,1 vs 15,2\%) em relação aos búfalos e nos inteiros (13,4 vs 14,1\%) em relação aos castrados. Não houve diferença para perda pelo resfriamento dos cortes da carcaça entre grupos genéticos e condição sexual. Concluiu-se que as diferenças entre bovinos e bubalinos independem da condição sexual e que os bubalinos apresentam menor rendimento de carcaça devido à maior proporção de cabeça, patas, couro e vísceras, embora estes apresentam maior proporção do corte serrote em função do peso da carcaça.
\end{abstract}

Palavras-chave: búfalo, bovino, carcaça, castrado, inteiro

\section{Carcass and Slaughter Yield of Castrated and Entire Buffaloes and Cattle}

\begin{abstract}
It was slaughtered 24 animals confined, being 8 ( 4 castrated and 4 entire) from each genetic group (Nelore, $1 / 2$ Nelore x Sindi cattle and e Mediterrâneos buffaloes), with $430 \mathrm{~kg}$ mean weight, in order to compare carcass and slaughter yield. Data obtained were analyzed statistically in a factorial scheme $3 \times 2$ ( 3 genetic groups $x 2$ sexual conditions) with 4 repetitions. Nelore and $1 / 2$ Nelore $x$ Sindi cattle presented smaller percentage of foot $(2.13,2.08 \mathrm{vs} 2,31 \%)$, head (3.99, 4.48 vs 5.04\%), hide (7.45, 8.21 vs $9.92 \%)$ and viscera $(25,6 ; 25,1$ vs $28,4 \%)$ than buffaloes, but no difference was observed for foot and viscera percentage among castrated and entire animals. Castrated animals presented hide with smaller percentage than entire ( 8.20 vs $8.85 \%)$, similar head percentage, being the tail percentage was higher in castrated animals ( 0.29 vs $0.26 \%)$. Carcasses of Nelore and $1 / 2$ Nelore x Sindi cattle reached higher yield (58.7 and 58.1 vs $52.3 \%$ ) than buffaloes, while castrated and entire dressing percentage was similar. Carcass and slaughter yield in relation of slaughter weight were higher on Nelore and $1 / 2$ Nelore x Sindi cattle than buffaloes: carcass (60.6 and 59.9 vs 54,1\%), hindquarter (27.98 and 27.1 vs $25.6 \%$ ), forequarter ( 24.8 and 24.9 vs $20.3 \%$ ) and similar side cut ( 7.82 and 7.83 vs $8.23 \%$ ), while entire presented higher forequarter $(23.9 \mathrm{vs} 22,8 \%$ ) than castrated. For carcass yield and their cuts in relation of carcass weight, Nelore and Nelore $\mathrm{x}$ Sindi cattle attained smaller hindquarter cut percentage than buffaloes $(46.7,45.9 \mathrm{vs} 47.8 \%$ ), while the castrated animals attained higher hindquarter percentage than entire (47.3 vs $46.3 \%)$. Nelore and Nelore $x$ Sindi cattle obtained higher forequarter cut percentage (40.7, 41.4 vs $37.4 \%$ ) than buffaloes, as well as entire animals $(40.7$ vs $38,9 \%$ ) in relation to castrated. Nelore and $1 / 2$ Nelore $x$ Sindi cattle presented smaller side cut percentage (12.9 and 13.1 vs $15.2 \%$ ) than buffaloes. For carcass cuts chilling loss there was no difference among genetics groups and sexual conditions. It was concluded that differences among cattle and buffaloes are independent of sexual condition and that buffaloes present smaller carcass yield because their higher proportion of foot, head, hide and viscera, though they present higher hindquarter proportion in function of carcass weight.
\end{abstract}

Key Words: buffalo, cattle, carcass, castrated, entire

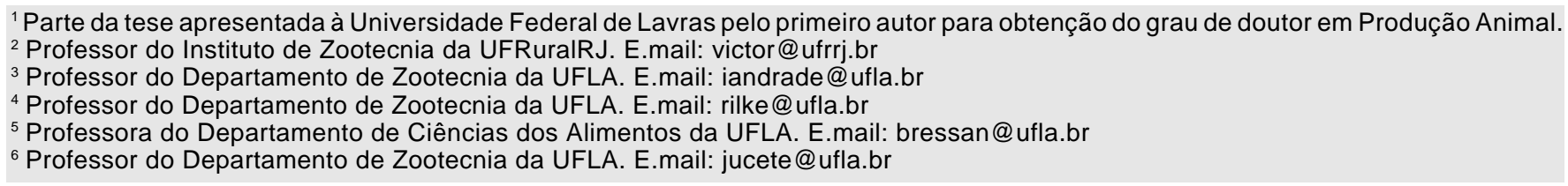




\section{Introdução}

O fator de maior importância na avaliação da carcaça é o rendimento, tanto da carcaça como dos cortes maiores com uma quantidade específica de gordura. O rendimento da carcaça depende primeiramente do conteúdo visceral que corresponde principalmente ao aparelho digestivo e que pode variar entre 8 a $18 \%$ do peso vivo (Sainz, 1996).

De acordo com Mattos et al. (1990), ao abaterem bovinos e búfalos com pesos semelhantes, verificaram diferença de até $5 \%$ no rendimento de carcaça a favor dos bovinos, devido ao couro mais espesso e pesado (1 a $2 \%$ ), chifres mais pesados e cerca de 2 a $3 \%$ a mais de conteúdo gastrintestinal dos búfalos. Em relação ao padrão de deposição de gordura, os búfalos apresentam acúmulo de gordura maior nas paredes do tórax e na cavidade abdominal, acúmulo menor entre grupos de músculo e menor ainda dentro dos músculos.

Resultados obtidos por vários autores, comparando a carcaça de búfalos e bovinos de diferentes grupos genéticos, indicaram o maior rendimento a favor dos bovinos (Lorenzoni et al., 1986, Moran \& Wood, 1986, Gazzetta et al., 1995; Jorge, 1993; Rezende et al., 1994; Velloso et al.,1994 e Lourenço Junior et al., 1997). Velloso et al. (1994) e Jorge (1993) atribuíram os resultados ao maior peso da cabeça, patas e pelo dos búfalos em relação aos bovinos.

Müller et al. (1994) trabalhando com bovinos Charolês e búfalos Mediterrâneos, abatidos com pesos semelhantes, obtiveram maior rendimento da carcaça e do corte serrote nos bovinos, respectivamente, $57,9 \%$ e $48,8 \%$ versus $53,1 \%$ e $47,4 \%$. O rendimento do quarto dianteiro foi maior nos búfalos (37,9 versus $37,0 \%$ ), não havendo diferença para o rendimento da ponta de agulha, $14,2 \%$ nos bovinos e $14,7 \%$ nos búfalos. Teixeira (1984) obteve resultados semelhantes para o grupo de búfalos, que apresentaram maior porcentual de corte serrote do que 3/4 Holandês x Zebu, enquanto Moran \& Wood, (1986) também obtiveram maior peso e rendimento do corte dianteiro e menor do corte traseiro em búfalos quando comparados aos bovinos. Gazzetta et al. (1995) obtiveram resultados semelhantes, incluindo um maior peso da ponta de agulha para búfalos. Em trabalho de Lourenço Jr. et al. (1997) com búfalos Mediterrâneos e bovinos Nelore, foi observado que bovinos alcançaram maior peso da carcaça fria (188,6 a 215,5 versus 146,6 a $187,4 \mathrm{~kg}$ ), perda pelo resfriamento e peso do conteúdo gastrintestinal semelhantes.
Lorenzoni et al. (1986) observaram que os búfalos apresentaram maior perda pelo resfriamento da carcaça $(2,09 \%)$ em relação aos demais grupos de bovinos, Nelore $(1,65 \%)$, Holandês $(1,35 \%), 1 / 2$ Holandês-Zebu $(1,41 \%), 3 / 4 \mathrm{HZ}(1,74 \%)$ e $]^{\mathrm{TM}} \mathrm{HZ}$ $(1,57 \%)$. Entretanto, Mattos et al. (1997) não encontraram diferença, trabalhando com zebuínos e búfalos, enquanto Lourenço Júnior et al. (1997) verificaram que a perda por resfriamento foi menor na carcaça de búfalos $(2,0$ a 2,4 $\mathrm{kg})$ do que em bovinos $(2,4$ a $3,2 \mathrm{~kg})$.

Mattos et al. (1997) encontraram maior rendimento de carcaça e peso do corte dianteiro nos bovinos Nelore em relação aos búfalos Mediterrâneo e Jafarabadi (56,9 vs 51,5 e $51,1 \%$ ), mas não obtiveram diferenças para o peso da carcaça, do corte traseiro e da ponta de agulha, enquanto o peso da cabeça, couro e patas foi maior nos búfalos.

Os grupos genéticos têm sido comparados dentro de uma mesma condição sexual, sendo necessário estabelecer se a castração interfere de maneira diferente dentro dos grupos de bovinos e bubalinos estudados.

A supressão dos testículos acarreta a regressão dos caracteres sexuais secundários ou uma paralisação no seu desenvolvimento, tudo dependendo da época e do modo de operar essa supressão, cujos efeitos serão maiores quanto mais novo for o animal. O desenvolvimento e a função das glândulas sexuais são dirigidos pelos hormônios gonadotrópicos e do funcionamento dessas glândulas depende o aparecimento dos caracteres sexuais secundários. Assim, o crescimento corporal prolonga-se até os 5 a 6 anos nos castrados, enquanto no animal não emasculado, o crescimento vai até os quatro anos e meio, considerando animais tardios. Nos animais inteiros, a musculatura fica mais desenvolvida, principalmente os quartos anteriores, pescoço e peito. Nos castrados, a altura fica maior, os quartos traseiros ficam mais desenvolvidos, havendo um quase equilíbrio entre estes e os anteriores, a bacia fica mais ampla e, de modo geral, o corpo se apresenta mais curto e engrossado, o esqueleto pesa menos e os ossos mais densos, a pele afina-se tendo como conseqüência o menor peso do couro (Domingues, 1968).

As diferenças sexuais observadas na composição da carcaça são similares entre raças, já que as diferenças mais importantes são o tamanho e a musculosidade. Os machos crescem mais rapidamente e depositam menos gordura que os machos castrados. Entre animais abatidos com a mesma 
idade, o inteiro produz uma carcaça mais pesada que o castrado, mas o conteúdo de gordura é menor no inteiro e maior no castrado (Sainz, 1996).

Em relação às carcaças de bovinos de origem européia, castrados e inteiros, apresentados por Morgan et al. (1993), não houve diferença para o rendimento, embora o peso da carcaça dos inteiros tenha sido superior. Búfalos inteiros alcançaram 50,4\% de rendimento de carcaça, enquanto castrados, $52,0 \%$ no trabalho de Drudi et al. (1976), que também encontraram peso da cabeça $(18,5$ e $18,1 \mathrm{~kg})$, do couro $(62,5$ e $57,1 \mathrm{~kg})$ e das patas $(9,01$ e $8,5 \mathrm{~kg})$ para inteiros e castrados, respectivamente.

Não há grande diferença no rendimento e na qualidade da carcaça entre búfalos castrados e inteiros até os dois anos de idade de acordo com Ferrara \& Infascelli (1994), os quais concluíram que é conveniente trazer os machos castrados para o mercado e que não é necessário esperar atingirem os três anos de idade para o abate. $\mathrm{O}$ rendimento da carcaça foi maior para os castrados (57,8 versus $56,7 \%)$ devido ao menor peso das patas e, particularmente, do couro, no qual a castração causou refinamento, tanto em búfalos como bovinos.

Em trabalho com búfalos Mediterrâneos castrados e inteiros, Minieri et al. (1972) verificaram rendimento de carcaça semelhante, 57,3 e 56,7\%, respectivamente, e maior proporção de pele nos animais inteiros. Bento et al. (1990) também não encontraram diferença entre parâmetros quantitativos da carcaça de búfalos Jafarabadi castrados com um ano de idade e inteiros, abatidos aos 24 meses de idade. Os resultados para rendimento de carcaça fria, do serrote, do dianteiro e do costilhar para castrados e inteiros, respectivamente, foram 50,3 e 49,6\%, 48,1 e 47,7\%, 37,3 e $38,2 \%$ e 14,5 e $14,0 \%$.

Estudando o efeito da castração em vários grupos genéticos de bovinos, Pádua et al. (2001) obtiveram maior peso do corte dianteiro nos inteiros $(75,9$ vs $74,1 \mathrm{~kg}$ ), enquanto os castrados apresentaram maior rendimento da carcaça (54,1 versus 51,6\%), maior grau de acabamento $(1,89$ vs 1,18$)$ e maior peso da ponta de agulha $(23,8$ vs $22,1 \mathrm{~kg})$. Entretanto, não houve diferença para o peso do corte serrote $(94,7$ versus $94,6 \mathrm{~kg}$ ).

No trabalho de Restle et al. (2000) com bovinos Charolês, Nelore e seus mestiços, os inteiros alcançaram peso da carcaça e porcentual do dianteiro superior aos castrados, enquanto os castrados apresentaram maior porcentual do corte serrote $(49,4$ versus
$48,5 \%)$ e do costilhar (13,6 versus $12,6 \%$ ), mas não houve diferença para o rendimento de carcaça $(55,9$ e $56,0 \%)$, quebra pelo resfriamento $(1,95$ e $1,92 \%)$ para castrados e inteiros, respectivamente. Macedo et al. (2000), trabalhando com búfalos Mediterrâneos, também não encontraram diferença entre castrados e inteiros para peso e rendimento de carcaça.

Como os estudos sobre a carcaça de bovinos e bubalinos castrados e inteiros, confinados sob mesmas condições ambientais, são ainda insuficientes para se precisar as diferenças entre esses grupos genéticos, objetivou-se com este trabalho, comparar: a composição da carcaça de bovinos Nelore e $1 / 2$ Nelore x Sindi e bubalinos Mediterrâneos e o efeito da castração.

\section{Material e Métodos}

Foram utilizados 24 novilhos com maturidade fisiológica de primeira dentição, que foram distribuídos em três grupos genéticos $(8$ bovinos da raça Nelore, 8 bovinos $1 / 2$ Nelore $\mathrm{x}$ Sindi e 8 búfalos Mediterrâneos) e duas condições sexuais (castrados e inteiros) com 4 repetições. Os animais foram confinados em baias coletivas de $300 \mathrm{~m}^{2}$ cada (lotação de 01 animal por $37,5 \mathrm{~m}^{2}$ ), isto é, em cada baia coletiva foram colocados oito animais. No início do período experimental, os grupos genéticos foram pesados e separados de acordo com a condição sexual. A instalação de confinamento utilizada apresenta piso de lajotas de pedra rejuntadas com concreto e cobertura meia-água de telha de amianto para proteção dos cochos e dos animais. Os bebedouros coletivos localizavam-se na divisória de duas baias coletivas e cada um media 2,0 $\mathrm{m}$ de comprimento, 0,60 $\mathrm{m}$ de largura para cada curralete, $0,30 \mathrm{~m}$ de profundidade e altura de $0,50 \mathrm{~cm}$.

Aos 70 dias antes do período experimental, 12 animais, quatro de cada grupo genético, foram escolhidos por sorteio para serem castrados. Antes do início do período de confinamento, os animais foram vacinados contra febre aftosa e receberam uma dose de vermífugo de amplo espectro.

Os animais receberam uma mesma dieta total à vontade para atendimento das exigências nutricionais recomendadas pelo National Research Council - NRC (1996), contendo $14,0 \%$ de proteína bruta e $50,0 \%$ de FDN, contendo capim elefante, resíduo de cervejaria, raspa de mandioca, cama de frango e sal mineral. Todo alimento fornecido era pesado diariamente, de acordo com a formulação proposta, e misturado no 
próprio cocho com auxílio de um forcado. Esta dieta foi fornecida uma vez ao dia, sempre às 7:00 horas e remexida às 15:30 horas. $\mathrm{O}$ sal mineral foi misturado ao concentrado, além de ter sido fornecido em cocho separado à vontade e as fezes acumuladas eram recolhidas semanalmente a fim de manter a higiene das baias e dos animais.

Os animais foram abatidos após jejum de 18 horas, cujos pesos médios de castrados e inteiros foram $419,9-448,9 \mathrm{~kg}( \pm 8,3 \mathrm{~kg}) \mathrm{kg}$ para bovinos Nelore, $407,2-454,0 \mathrm{~kg}( \pm 8,3 \mathrm{~kg})$ para $1 / 2$ Nelore $\mathrm{x}$ Sindi e 449,8-445,6 kg ( $\pm 8,3 \mathrm{~kg})$ para búfalos Mediterrâneo. O abate dos bovinos foi realizado pelo processo tradicional, com insensibilização mecânica. Para o abate dos búfalos, o atordoamento foi realizado pela enervação, através do rompimento da conexão encéfalo-medula. Imediatamente após a insensibilização foi realizada a sangria, mediante um corte sagital da barbela, ruptura da musculatura e secção dos grandes vasos do pescoço. Em seguida foi realizada a esfola aérea (retirada do couro com o animal suspenso de cabeça para baixo), serramento do esterno e a evisceração. Terminada a evisceração, as carcaças foram divididas com serra elétrica ao longo da coluna vertebral, restando duas meias carcaças. A separação do corte traseiro do dianteiro foi realizada com um corte entre a $5^{\mathrm{a}}$ e $6^{\mathrm{a}}$ costelas e a ponta de agulha foi separada do traseiro, partindo o corte da virilha, dirigindo-se para o lombo e seguindo paralelamente a linha dorsal a uma distância média de $20 \mathrm{~cm}$ da coluna vertebral, mais os músculos abdominais (Barros e Vianni, 1979). Os cortes comerciais da carcaça foram levados à câmara fria, onde permaneceram por 48 horas, quando foram pesados para obtenção do peso frio.

As determinações objetivas dos cortes do abate como porcentagem da cabeça, patas, couro, vísceras e cauda, rendimento da carcaça, do corte traseiro, dianteiro e costilhar foram obtidas em relação ao peso de abate, sendo que também foram obtidos os rendimentos da carcaça e dos cortes da carcaça em relação ao peso da própria carcaça, expressos em porcentagem do peso.

A quebra no resfriamento foi determinada pela diferença de peso dos cortes da carcaça fria após 48 horas de resfriamento ao atingir uma temperatura de $1^{\circ} \mathrm{C}$ em relação à carcaça quente, expresso em porcentagem.

O peso das patas, obtido após o abate e secionadas na altura da articulação carpo-metacarpiana e da articulação tarso-metatarsiana para dianteiras e tra- seiras, respectivamente, em relação ao peso vivo, enquanto o porcentual de vísceras foi determinado pelo peso do trato gastrintestinal, órgãos e gorduras perirrenal e inguinal, expressos em porcentagem do peso vivo.

O delineamento experimental adotado foi esquema fatorial $3 \times 2$ (três grupos genéticos $\mathrm{x}$ duas condições sexuais) com quatro repetições, apresentando seis tratamentos, tendo o peso de abate como coeficiente de regressão.

\section{Resultados e Discussão}

Os resultados das medidas de rendimento de abate de acordo com o grupo genético e a condição sexual estão apresentados na Tabela 1. Não ocorreu interação $(\mathrm{P}>0,05)$ entre grupo genético e condição sexual para todas as variáveis estudadas. Entretanto, houve diferença $(\mathrm{P}<0,05)$ entre grupos genéticos para peso da carcaça, rendimento das patas, cabeça, couro, vísceras, carcaça, corte serrote e corte dianteiro, não havendo diferença estatística $(\mathrm{P}>0,05)$ para porcentagem da cauda e do corte costilhar.

Para animais castrados e inteiros ocorreu diferença $(\mathrm{P}<0,05)$ para peso da carcaça, porcentagem do couro, rabada e rendimento do corte dianteiro, enquanto não houve diferença $(\mathrm{P}>0,05)$ para porcentagem de patas, cabeça, vísceras e rendimento da carcaça e dos cortes serrote, dianteiro e costilhar.

Os búfalos apresentaram maior porcentagem de patas, cabeça, couro e vísceras em relação aos bovinos, com rendimento da cauda semelhante entre os grupos genéticos. Os bovinos apresentaram maior peso e rendimento da carcaça quente, maior rendimento dos cortes serrote e dianteiro e um menor valor para o corte costilhar em relação aos búfalos. Entre os dois grupos de bovinos houve diferença $(\mathrm{P}<0,05)$ apenas para rendimento da cabeça, onde os bovinos $1 / 2$ Nelore x Sindi apresentaram maior porcentual em relação aos bovinos Nelore.

Os animais castrados apresentaram menor porcentual de couro, menor rendimento do corte dianteiro e maior porcentual de cauda em relação aos inteiros, não havendo diferença $(\mathrm{P}>0,05)$ para porcentual das patas, isto é, animais inteiros apresentaram patas semelhantes aos animais castrados.

O rendimento da cabeça dos búfalos foi $1,05 \%$ a mais em relação aos bovinos Nelore e $0,56 \%$ a mais em relação aos $1 / 2$ Nelore $x$ Sindi. Entre os dois grupos de bovinos a diferença foi de $0,49 \%$ a mais de rendimento para o $1 / 2$ Nelore x Sindi, indicando da 
Tabela 1 - Rendimentos do abate de acordo com o grupo genético e a condição sexual Table 1 - Slaughter yield according to genetic group and sexual condition

\begin{tabular}{|c|c|c|c|c|c|c|}
\hline \multirow[t]{2}{*}{$\begin{array}{l}\text { Variável } \\
\text { Variable }\end{array}$} & \multicolumn{3}{|c|}{$\begin{array}{l}\text { Grupo genético } \\
\text { Genetic group }\end{array}$} & \multicolumn{2}{|c|}{$\begin{array}{l}\text { Condição sexual } \\
\text { Sexual condition }\end{array}$} & \multirow[t]{2}{*}{$\mathrm{CV} \%$} \\
\hline & $\begin{array}{c}\text { Nelore } \\
\text { Nelore cattle }\end{array}$ & $\begin{array}{l}1 / 2 \text { Nelore x Sindi } \\
1 / 2 \text { Nelore } x \text { Sindi cattle }\end{array}$ & $\begin{array}{l}\text { Búfalo mediterrâneo } \\
\text { Mediterraneanbuffalo }\end{array}$ & $\begin{array}{l}\text { Castrado } \\
\text { Castrated }\end{array}$ & $\begin{array}{l}\text { Inteiro } \\
\text { Entire }\end{array}$ & \\
\hline $\begin{array}{l}\text { Peso abate, } \mathrm{kg} \\
\text { Slaughter weight, } \mathrm{kg}\end{array}$ & 434,4 & 430,6 & 447,4 & 425,5 & 449,5 & 3,81 \\
\hline $\begin{array}{l}\text { Peso carcaça, kg } \\
\text { Carcass weight, } \mathrm{kg}\end{array}$ & $262,9 \mathrm{~A}$ & $257,8 \mathrm{~A}$ & $242,0 \mathrm{~B}$ & $246,6 \mathrm{~b}$ & $261,8 \mathrm{a}$ & 4,28 \\
\hline $\begin{array}{l}\text { Patas, \% } \\
\text { Feet, } \%\end{array}$ & $2,13 \mathrm{~B}$ & $2,08 \mathrm{~B}$ & $2,31 \mathrm{~A}$ & $2,20 \mathrm{a}$ & $2,15 \mathrm{a}$ & 6,88 \\
\hline $\begin{array}{l}\text { Cabeça, \% } \\
\text { Head, \% }\end{array}$ & $3,99 \mathrm{C}$ & $4,48 \mathrm{~B}$ & $5,04 \mathrm{~A}$ & $4,40 \mathrm{a}$ & 4,61 a & 7,53 \\
\hline $\begin{array}{l}\text { Couro, } \% \\
\text { Hide, } \%\end{array}$ & 7,44 B & $8,20 \mathrm{~B}$ & $9,92 \mathrm{~A}$ & $8,20 \mathrm{~b}$ & 8,85 a & 8,61 \\
\hline $\begin{array}{l}\text { Vísceras, \% } \\
\text { Viscera, } \%\end{array}$ & $25,60 \mathrm{~B}$ & $25,09 \mathrm{~B}$ & $28,39 \mathrm{~A}$ & $26,84 \mathrm{a}$ & $25,87 \mathrm{a}$ & 9,59 \\
\hline $\begin{array}{l}\text { Cauda, \% } \\
\text { Pigpigtail, \% }\end{array}$ & $0,27 \mathrm{~A}$ & $0,29 \mathrm{~A}$ & $0,26 \mathrm{~A}$ & $0,29 \mathrm{a}$ & $0,26 \mathrm{~b}$ & 12,49 \\
\hline $\begin{array}{l}\text { Carcaça, \% } \\
\text { Carcass, \% }\end{array}$ & $60,56 \mathrm{~A}$ & $59,86 \mathrm{~A}$ & $54,08 \mathrm{~B}$ & 58,07 a & 58,26 a & 3,85 \\
\hline $\begin{array}{l}\text { Serrote, \% } \\
\text { Hindquarter, \% }\end{array}$ & $27,98 \mathrm{~A}$ & $27,10 \mathrm{~A}$ & $25,57 \mathrm{~B}$ & $27,16 \mathrm{a}$ & $26,60 \mathrm{a}$ & 4,11 \\
\hline $\begin{array}{l}\text { Dianteiro, } \% \\
\text { Forequarter, } \%\end{array}$ & $24,76 \mathrm{~A}$ & $24,94 \mathrm{~A}$ & $20,27 \mathrm{~B}$ & $22,76 \mathrm{~b}$ & $23,89 \mathrm{a}$ & 5,43 \\
\hline $\begin{array}{l}\text { Costilhar, \% } \\
\text { Side cut, \% }\end{array}$ & $7,82 \mathrm{~A}$ & $7,83 \mathrm{~A}$ & $8,23 \mathrm{~A}$ & 8,15 a & 7,77 a & 6,80 \\
\hline
\end{tabular}

Médias seguidas pela mesma letra na linha, maiúsculas para grupo genético e minúsculas para condição sexual, não diferem significativamente $(P>0,05)$ pelos testes de SNK e $F$, respectivamente.

Averages followed by same letter, upper case for genetic group and lower case for sexual condition, do not differ significatively $(P>.05)$ by SNK and $F$ test, respectively.

mesma forma que a maior pressão de melhoramento foi efetivada nos bovinos Nelore, mostrando que essa raça foi selecionada para apresentar uma cabeça proporcionalmente menor em relação ao corpo e cortes comerciais.

Para o porcentual do couro, houve diferença $(\mathrm{P}<0,05)$ entre grupos genéticos e condição sexual para média dos três grupos, com búfalos apresentando maior rendimento do que bovinos. $\mathrm{O}$ couro de búfalos foi $2,47 \%$ maior em relação ao couro de bovinos Nelore e $1,71 \%$ a mais em relação ao couro de bovinos $1 / 2$ Nelore x Sindi. Houve uma pequena diferença entre os dois grupos de bovinos de $0,76 \%$ a mais tendendo para bovinos $1 / 2$ Nelore x Sindi, uma vez que essa diferença não foi estatística. Os animais inteiros apresentaram rendimento do couro $0,65 \%$ a mais em relação aos castrados. Essa diferença está de acordo com Domingues (1968) e Ferrara \& Infascelli (1994), que registraram o refinamento do couro causado pela castração. Os resultados para peso do couro também concordam com Domingues, (1968), registrando que a pele dos animais castrados afina-se, tendo como conseqüência o menor peso do couro. Esse refinamento pode trazer como conseqüência positiva, a melhoria do rendimento e dos cortes da carcaça. Esses resultados estão em concordância com os de Drudi et al. (1976), que também encontraram couro e patas mais pesados em búfalos inteiros.

Os búfalos apresentaram maior rendimento das vísceras, cerca de $2,8 \%$ a mais que bovinos Nelore e $3,3 \%$ a mais que bovinos $1 / 2$ Nelore $x$ Sindi. Esses resultados estão indicando a melhor condição dos bovinos para obtenção de uma carcaça de melhor qualidade. Por outro lado, o maior porcentual de vísceras pode estar indicando uma maior capacidade digestiva dos búfalos, com possíveis respostas positivas sobre o ganho de peso. Além disso, os búfalos apresentam, normalmente, maior amplitude torácica que bovinos, e essa característica pode ter proporcionado maior porcentual de vísceras, além de ter influenciado o peso do couro.

Os animais castrados apresentaram cauda com maior rendimento que inteiros, considerando ainda que na média geral os castrados apresentaram rendi- 
mento superior com cerca de $0,03 \%$ a mais. Esses resultados estão indicando que a castração faz aumentar o porcentual de cauda, possivelmente pela falta da ação dos hormônios androgênicos. De acordo com Domingues (1968) a castração causa ampliação da bacia, fazendo o corpo se apresentar mais curto e engrossado. $\mathrm{O}$ maior porcentual da cauda pode ter ocorrido juntamente com o aumento da amplitude da bacia, embora não tenha ocorrido uma diferença direta para o rendimento do corte serrote (traseiro especial) entre castrados e inteiros. Por outro lado, ocorreu uma diferença indireta, visto que os animais castrados apresentaram menor rendimento do corte dianteiro, portanto, maior rendimento do corte traseiro em relação ao dianteiro, proporcionalmente.

Bovinos Nelore e $1 / 2$ Nelore $x$ Sindi apresentaram maior rendimento da carcaça quente que búfalos Mediterrâneos $(\mathrm{P}<0,05)$. Ao se comparar o rendimento de carcaça quente de bovinos Nelore com a de búfalos verifica-se uma diferença de $6,48 \%$, enquanto os bovinos $1 / 2$ Nelore $\mathrm{x}$ Sindi alcançaram uma diferença menor, cerca de 5,78\% a mais em relação aos búfalos. Não houve diferença $(\mathrm{P}>0,05)$ para rendimento de carcaça quente entre os dois grupos de bovinos. Naturalmente, que essas diferenças representam uma vantagem a favor dos bovinos, especialmente quando o abate de um grande número de animais é realizado. Isto é, quanto maior o rendimento da carcaça, maior deve ser a proporção de sua porção comestível. Esses resultados estão de acordo com os obtidos por Lourenço Júnior et al. (1997) e Muller et al. (1994), mas estão diferentes dos resultados encontrados por Mattos et al. (1997), que não observaram diferença para o peso da carcaça quente, trabalhando com bovinos Nelore e búfalos Mediterrâneos e Jafarabadi.

O maior rendimento de carcaça dos bovinos está diretamente relacionado ao maior peso das patas, cabeça, couro e vísceras dos búfalos, que acabam promovendo uma diminuição no rendimento de carcaça destes animais. É muito provável que o maior rendimento de carcaça dos bovinos esteja relacionado à maior pressão de melhoramento ocorrida nesses animais, especialmente no caso dos zebuínos, que contam com uma associação de criadores bastante ativa com projetos de melhoramento.

Embora não tenha havido diferença para rendimento de carcaça entre animais inteiros e castrados, é necessário observar que os animais inteiros apresentaram carcaça mais pesada e isso tem reflexos positivos, indicando que os animais inteiros são mais eficientes em ganho de carcaça que castrados, fazendo grande diferença quando o abate é realizado para grande número de animais.

Para o rendimento do corte serrote quente em relação ao peso de abate (Tabela 1 ), verifica-se que houve diferença dentro dos grupos genéticos $(\mathrm{P}<0,05)$, mas não houve efeito da condição sexual $(\mathrm{P}>0,05)$. Os búfalos apresentaram a menor proporção do corte serrote em relação aos dois grupos de bovinos, cujas diferenças foram de $2,41 \%$ e de $1,53 \%$ em relação aos bovinos Nelore e 1/2 Nelore x Sindi, respectivamente. Entre os dois grupos de bovinos não houve diferença para rendimento do corte serrote $(\mathrm{P}>0,05)$. Animais castrados e inteiros apresentaram rendimento do corte serrote em relação ao peso de abate semelhante.

O rendimento do corte dianteiro quente em relação ao peso de abate (Tabela 1) apresentou diferença entre grupos genéticos e condição sexual $(\mathrm{P}<0,05)$. Os búfalos apresentaram o menor rendimento desse corte, cuja diferença a favor dos bovinos Nelore foi de $4,49 \%$ e dos bovinos 1/2 Nelore x Sindi foi de 4,67\%. Entre os dois grupos de bovinos não houve diferença $(\mathrm{P}>0,05)$ para esse corte. Para a condição sexual a diferença a favor dos inteiros foi de $1,13 \%$ em relação aos castrados.

Possivelmente, essa diferença seja devido à maior musculosidade apresentada pelos bovinos, especialmente, os inteiros. O maior peso do corte dianteiro para os animais inteiros já era esperado, uma vez que esses animais apresentam maior desenvolvimento devido às características sexuais secundárias, que proporcionam um maior desenvolvimento dos músculos do peito, do pescoço e das paletas. De acordo com Domingues (1968), o macho inteiro possui a musculatura anterior do corpo mais desenvolvida, principalmente nos quartos anteriores, no pescoço e no peito.

Para o rendimento do corte costilhar em relação ao peso de abate (Tabela 1), não houve diferença estatística $(\mathrm{P}>0,05)$ entre grupos genéticos e condição sexual, embora os búfalos tenham apresentado uma tendência de maior rendimento em relação aos dois grupos de bovinos, cuja diferença foi de 0,41 e de $0,4 \%$ para o grupo de Nelore e $1 / 2$ Nelore $x$ Sindi, respectivamente.

Para o rendimento dos três cortes comerciais (serrote, dianteiro e costilhar) em relação ao peso da carcaça quente (Tabela 2), não houve interação $(\mathrm{P}>0,05)$ entre grupos genéticos e condição sexual, ocorrendo diferença $(\mathrm{P}<0,05)$ entre grupos genéticos e entre castrados e inteiros.

Para o corte serrote, os búfalos apresentaram 
Tabela 2 - Rendimentos dos cortes comerciais em relação ao peso da carcaça quente, de acordo com o grupo genético e a condição sexual

Table 2 - Commercial cuts yield in relation of hot carcass weight, according to genetic group and sexual condition

\begin{tabular}{|c|c|c|c|c|c|c|}
\hline \multirow[t]{2}{*}{$\begin{array}{l}\text { Variável } \\
\text { Variable }\end{array}$} & \multicolumn{3}{|c|}{$\begin{array}{l}\text { Grupo genético } \\
\text { Genetic group }\end{array}$} & \multicolumn{2}{|c|}{$\begin{array}{l}\text { Condição sexual } \\
\text { Sexual condition }\end{array}$} & \multirow[t]{2}{*}{$\mathrm{CV} \%$} \\
\hline & $\begin{array}{c}\text { Nelore } \\
\text { Nelore cattle }\end{array}$ & $\begin{array}{c}1 / 2 \text { Nelore } \mathrm{x} \text { Sindi } \\
1 / 2 \text { Nelore } x \text { Sindi cattle }\end{array}$ & $\begin{array}{l}\text { Búfalo mediterrâneo } \\
\text { Mediterraneanbuffalo }\end{array}$ & $\begin{array}{l}\text { Castrado } \\
\text { Castrated }\end{array}$ & $\begin{array}{l}\text { Inteiro } \\
\text { Entire }\end{array}$ & \\
\hline $\begin{array}{l}\text { Serrote, } \% \\
\text { Hindquarter, \% }\end{array}$ & $\begin{array}{c}46,21 \mathrm{AB} \\
2,52\end{array}$ & $45,28 \mathrm{~B}$ & $47,29 \mathrm{~A}$ & $46,80 \mathrm{a}$ & $45,72 \mathrm{~b}$ & \\
\hline $\begin{array}{l}\text { Dianteiro, \% } \\
\text { Forequarter, \% }\end{array}$ & $40,88 \mathrm{~A}$ & $41,64 \mathrm{~A}$ & $37,50 \mathrm{~B}$ & $39,12 \mathrm{~b}$ & $40,89 \mathrm{a}$ & 3,37 \\
\hline $\begin{array}{l}\text { Costilhar, \% } \\
\text { Side cut, \% }\end{array}$ & $12,91 \mathrm{~B}$ & $13,08 \mathrm{~B}$ & $15,21 \mathrm{~A}$ & $14,08 \mathrm{a}$ & $13,39 \mathrm{~b}$ & 4,88 \\
\hline
\end{tabular}

Médias seguidas pela mesma letra na linha, maiúsculas para grupo genético e minúsculas para condição sexual, não diferem significativamente $(\mathrm{P}>0,05)$ pelos testes SNK e $\mathrm{F}$, respectivamente.

Averages followed by same letter, upper case for genetic group and lower case for sexual condition, do not differ significatively (P>.05) by SNK and $F$ test, respectively.

maior rendimento juntamente com o grupo de bovinos Nelore, enquanto bovinos $1 / 2$ Nelore x Sindi apresentaram o menor rendimento sem apresentar diferença com os corte serrote dos bovinos Nelore. Este corte apresentou maior rendimento nos animais castrados em relação aos inteiros. A diferença para o corte serrote de búfalos em relação aos bovinos Nelore foi de $1,08 \%$ e aos bovinos $1 / 2$ Nelore x Sindi foi de $2,01 \%$. Para condição sexual, os animais castrados apresentaram corte serrote $1,08 \%$ a mais de rendimento em relação aos inteiros.

Essa vantagem é reforçada pela castração, que permite um aumento da proporção do corte serrote. Teixeira (1984) obteve resultados semelhantes para o grupo de búfalos, que apresentaram maior porcentual de corte serrote do que 3/4 Holandês x Zebu. Müller et al. (1994) e Moran \& Wood, (1986) obtiveram resultados semelhantes, com rendimento do corte serrote maior nos bovinos, enquanto Mattos et al. (1997) e Bento et al. (1990) não encontraram diferença para o corte serrote, trabalhando com búfalos castrados e inteiros. Pádua et al. (2001) também não obtiveram diferença para o corte serrote entre bovinos inteiros e castrados.

Para o corte dianteiro, os dois grupos de bovinos apresentaram maior rendimento que búfalos, mas não houve diferença $(\mathrm{P}>0,05)$ entre os dois grupos de bovinos. A diferença a mais para bovinos Nelore e $1 / 2$ Nelore x Sindi em relação aos búfalos foi de 3,38\% e $4,14 \%$, respectivamente. Para condição sexual, a diferença foi de $1,77 \%$ a mais de rendimento do corte dianteiro a favor dos animais inteiros.
Teixeira (1984) obteve resultado diferente, com maior porcentual de corte dianteiro nos bovinos, enquanto Müller et al. (1994), Moran \& Wood, (1986) e Gazzetta et al (1995) obtiveram rendimento do dianteiro maior nos búfalos. Bento et al. (1990) não obtiveram diferença entre búfalos castrados e inteiros para rendimento dos cortes, enquanto Pádua et al. (2001), trabalhando com bovinos, obtiveram maior peso e rendimento nos animais inteiros.

Para o corte costilhar, os búfalos apresentaram maior rendimento que bovinos Nelore e $1 / 2$ Nelore $x$ Sindi, não ocorrendo diferença entre os dois grupos de bovinos. Os búfalos apresentaram maior rendimento do corte costilhar que bovinos Nelore e $1 / 2$ Nelore x Sindi, com diferença de 2,3 e 2,13\%, respectivamente. Para condição sexual, o rendimento do corte costilhar dos animais castrados foi maior que inteiros, cerca de $0,69 \%$ de diferença.

Müller et al. (1994) não obtiveram diferença para o rendimento da ponta de agulha de búfalos e bovinos. Gazzetta et al. (1995) obtiveram resultados semelhantes, com maior proporção da ponta de agulha na carcaça de búfalos. Mattos et al. (1997) não encontraram diferença para rendimento da ponta de agulha entre búfalos e bovinos, enquanto Bento et al. (1990) não encontraram diferença entre búfalos inteiros e castrados para rendimento da ponta de agulha.

Morgan et al. (1993) e Restle et al. (2000) também encontraram maior rendimento da carcaça em bovinos inteiros, enquanto Pádua et al. (2001) obtiveram maior peso e rendimento na carcaça de bovinos castrados. Entretanto, Macedo et al. (2000) não 
encontraram diferença entre búfalos castrados e inteiros para peso e rendimento da carcaça quente.

Esses resultados estão de acordo com a maioria dos autores, os quais apresentaram maior rendimento a favor dos bovinos (Lorenzoni et al., 1986; Moran \& Wood, 1986; Gazzetta et al., 1995; Jorge, 1993; Müller et al., 1994; Rezende et al., 1994a; Velloso et al.,1994; Lourenço Jr. et al., 1997). Em relação ao observado por Mattos et al. (1990), há concordância de resultados, relatando que ao se abater bovinos e búfalos com pesos semelhantes, percebe-se uma diferença de até $5 \%$ no rendimento de carcaça a favor dos bovinos, embora os resultados do presente trabalho tenham mostrado uma diferença de 5\%.

Em trabalhos com búfalos somente, alguns autores verificaram resultados diferentes como maior rendimento nos castrados (Drudi et al., 1976; Ferrara \& Infascelli, 1994). Rendimentos semelhantes foram obtidos por Minieri et al. (1972), Bento et al. (1990) e Macedo et al. (2000). Em trabalhos com bovinos, Pádua et al. (2001) obtiveram maior rendimento em castrados, enquanto Morgan et al. (1993) e Restle et al. (2000), não encontraram diferença entre castrados e inteiros.

Esses resultados demonstram que os búfalos apresentaram carcaça com rendimento inferior por apresentar patas, cabeça, couro e vísceras mais pesados e que a castração causa nos grupos estudados um refinamento do couro, com maior efeito sobre os búfalos. Mattos et al. (1990) justificaram o menor rendimento dos búfalos em função do couro mais espesso e pesado ( 1 a $2 \%$ ), chifres mais pesados e cerca de 2 a $3 \%$ a mais de conteúdo gastrintestinal nos búfalos. Velloso et al. (1994) e Jorge (1993), comparando búfalos e bovinos também justificaram o menor rendimento de carcaça do búfalo devido à cabeça, pés e pele mais pesados.

Em relação à condição sexual, há concordância com as observações de Domingues (1968), cujos animais castrados apresentam pele mais fina, cabeça e patas mais leves e esses fatores podem melhorar o rendimento da carcaça. Ferrara \& Infascelli (1994) justificaram o maior rendimento da carcaça nos animais castrados devido ao menor peso dos patas e, particularmente do couro, considerando que a castração causa um refinamento tanto em búfalos quanto em bovinos.

Esses resultados eram esperados, uma vez que búfalos apresentam patas e couro mais pesados que bovinos, como uma adaptação da espécie às regiões úmidas e de pântanos, onde muitas vezes os bovinos não conseguem se adaptar.
Para quebra pelo resfriamento dos cortes da carcaça (serrote, dianteiro e costilhar) não houve diferença $(\mathrm{P}>0,05)$ entre grupos genéticos e efeito da condição sexual, cujos valores variaram de 1,70 a $2,07 \%$ para o corte serrote, de 3,44 a 3,73 para o corte dianteiro e de 5,26 a 5,90\% para o corte costilhar.

Resultados semelhantes foram obtidos por Lourenço Jr. et al. (1997) com búfalos e bovinos e por Restle et al. (2000) com bovinos em que não houve diferença para quebra de resfriamento, enquanto Lorenzoni et al. (1986) observaram que os búfalos apresentaram maior perda pelo resfriamento da carcaça.

\section{Conclusões}

Os bovinos apresentaram maior rendimento de carcaça que bubalinos devido ao menor peso do couro, cabeça, patas e vísceras.

A castração promoveu diminuição do porcentual do couro e do dianteiro, sem afetar o rendimento de carcaça.

Búfalos Mediterrâneos tiveram maior proporção do corte traseiro e menor proporção do corte dianteiro que bovinos Nelore e $1 / 2$ Nelore x Sindi em relação ao peso da carcaça.

\section{Literatura Citada}

BARROS, G.C.; VIANNI, M.C.E. Tecnologia aplicada às carnes bovina, suína e de aves, da produção ao consumo. Seropédica: Universidade Federal Rural do Rio de Janeiro, 1979. 116p.

BENTO, C.L.R.; MEDEIROS, E.L.; COSTA, N.L. Efeito da idade à castração sobre o desenvolvimento e qualidade da carcaça de bubalinos. In: REUNIÃO DA SOCIEDADE BRASILEIRA DE ZOOTECNIA, 27., 1990, Campinas. Anais... Campinas: Sociedade Brasileira de Zootecnia, 1990. p. 445 .

DOMINGUES, O. Introdução à zootecnia Rio de Janeiro: Serviço de Informação Agrícola, 1968. 392p.

DRUDI, A.; MATTOS, J.C.A.; PEREIRA, W.M. et al. Avaliação do desempenho e do rendimento das carcaças de búfalos, Bubalus bubalis L., de sobreano, castrados e não castrados. Zootecnia, n.14, v.3, p.139-147, 1976.

FERRARA, B.; INFASCELLI, F. Buffalo meat production: Consumption, quality, carcass, sub-products. In: CONGRESSO MUNDIAL DE BÚFALOS, 4., 1994, São Paulo. Proceedings... São Paulo: FAO/FINEP, 1994. v.1, p.122-136.

GAZZETTA, M.C.R.R.; ITURRINO, R.B.S.; CAMPOS, B.E.S. de et al. Avaliação corporal de búfalos (Bubalus bubalis) e bovinos Nelore (Bos indicus), terminados em confinamento. Boletim de Indústria Animal, v.52, n.1, p.77-86, 1995.

JORGE, A.M. Ganho de peso, conversão alimentar e características de carcaça de bovinos e bubalinos. Viçosa, MG: Universidade Federal de Viçosa, 1993. 97p. Dissertação (Mestrado em Zootecnia) - Universidade Federal de Viçosa, 1993. 
LORENZONI, W.R.; CAMPOS, J.; GARCIA, J.A. et al. Ganho de peso, eficiência alimentar e qualidade da carcaça de novilhos búfalos, Nelores, Holandeses e mestiços Holandês-Zebu. Revista da Sociedade Brasileira de Zootecnia, v.15, n.6, p.486-497, 1986.

LOURENÇO JR., J.B.; SÁ, T.D.A.; SIMÃO-NETO, M. et al. Environmental effects on cattle and buffaloes in cultivated pasture of Marajo island, Brazil. In: WORLD BUFFALO CONGRESS, 5., 1997, Caserta. Proceedings... Caserta: FAO/IBF, 1997. p.424-427.

MACEDO, M.P.; BIANCHINI SOBRINHO, E.; RESENDE, F.D. et al. Características de carcaça de bubalinos da raça Mediterrâneo terminados em diferentes regimes alimentares. In: REUNIÃO ANUAL DA SOCIEDADE BRASILEIRA DE ZOOTECNIA, 37., 2000, Viçosa, MG.Anais... Viçosa: Sociedade Brasileira de Zootecnia, 2000. CD-ROM de resumos expandidos 2000.

MATTOS, J.C.A.; NOGUEIRA, J.R.; OLIVEIRA, A.A.D. et al. Comparison on carcass, meat cuts and some meat quality characteristics of buffaloes and of zebu. In: WORLD BUFFALO CONGRESS, 5., 1997, Caserta. Proceedings... Caserta: FAO/IBF, 1997. p.442-446.

MATTOS, J.C.A.; GUTMANIS, D.; MATTOS, A.C. Características da carcaça e da carne de bubalinos (Conferências). In: REUNIÃO ANUAL DA SOCIEDADE BRASILEIRA DE ZOOTECNIA, 27., 1990, Campinas. Anais... Piracicaba: Sociedade Brasileira de Zootecnia, 1990. p.711-737.

MINIERI, L.; FRANCISCIS, G.; BARBIERI, V. et al. Prove di macellazione nel vitellone bufalino intero e castrato. Acta Medica Veterinaria, v.18, p.19-33, 1972.

MORAN, J.B.; WOOD, J.T. Comparative performance of five genotypes of Indonesian large ruminants. 3. Growth and development of carcass tissues (cattle breeds; buffaloes). Australian Journal of Agricultural Research, v.37, n.4, p.435-447, 1986.

MORGAN, J.B.; WHEELER, T.L.; KOOHMARAIE, M. et al. Meat tenderness and the calpain proteolytic system in longissimus muscle of young bulls and steers. Journal of Animal Science, v.71, n.6, p.1471-1476, 1993.

MÜLLER, L.; AGUIRRE, L.F.; RESTLE, J. et al. Carcass and meat quality of cattle and buffalo. In: WORLD BUFFALO CONGRESS, 4, 1994, São Paulo.Proceedings... São Paulo: FAO/FINEP, 1994. v.2, p.130-132.
NATIONAL RESEARCH COUNCIL - NRC. Nutrient requirements of beef cattle. 7.ed. Washington, D.C.: 1996. 242p.

PÁDUA, J.T.; SAINZ, R.D.; PRADO, C.S. et al. Efeitos de grupos genéticos, castração e anabolizantes no desempenho e nas carcaças de bovinos. In: REUNIÃO ANUAL DA SOCIEDADE BRASILEIRA DE ZOOTECNIA, 38., 2001. Piracicaba. Anais... Piracicaba: Sociedade Brasileira de Zootecnia, 2001. p.1518-1519.

RESTLE, J.; VAZ, F.N.; FEIJÓ, G.L.D. et al. Características de carcaça de bovinos inteiros ou castrados de diferentes composições raciais Charolês x Nelore. Revista Brasileira de Zootecnia, v.29, n.5, p.1371-1379, 2000.

REZENDE, G.C.; LUCHIARI FILHO, A.; ALEONI, G. et al. Características de carcaça de novilhos taurinos e zebuínos e bubalinos, terminados em confinamento. II. Rendimento de carcaça. In: REUNIÃO ANUAL DA SOCIEDADE BRASILEIRA DE ZOOTECNIA, 31., 1994, Maringá. Anais... Maringá: Sociedade Brasileira de Zootecnia, 1994. p.190.

SAINZ, R.D. Qualidade das carcaças e da carne bovina. In: CONGRESSO BRASILEIRO DAS RAÇAS ZEBUÍNAS, 2., 1996, Uberaba. Anais... Uberaba: ABCZ, 1996. (não paginado).

TEIXEIRA, J.C. Exigências de energia e proteína, composição e área corporal e principais cortes da carcaça em seis grupos genéticos de bovídeos. Viçosa, MG: Universidade Federal de Viçosa, 1984. 94p. Tese (Doutorado em Zootecnia) - Universidade Federal de Viçosa.

VELLOSO, L.; SCHALCH, E.; ZANETTI, M.A. et al. Comparative performance of buffalo, zebu (Nelore) e Holstein steers, fed crude soybean meal, dry cassava meal and ground sugar-cane in a feedlot trial. In: WORLD BUFFALO CONGRESS, 4., 1994, São Paulo.Proceedings... SãoPaulo: FAO/FINEP, 1994. v.2, p.266-268.

Recebido em: 23/07/02

Aceito em: 20/11/02 